\title{
Planisfério da interculturalidade
}

\section{Museus e mediação: novos espaços e possibilidades de mudança}

\author{
Intercultural planisphere
}

Museums and mediation: new spaces and possibilities for change

Joana Macedoi

Faculdade de Belas Artes da Universidade do Porto

\section{Resumo}

A partir de um relato da experiência adquirida como voluntária num projeto comunitário desenvolvido pela Casa da Cerca, uma instituição museológica em Almada, Portugal, pretende-se principalmente refletir sobre a forma como ele questiona a ação dos Serviços Educativos, ajudando a desenhar novos contextos e possibilidades. A construção de um Planisfério Intercultural, um mural de azulejos realizados manualmente, pensado como projeto de arte pública comunitária, é desenvolvido no campo da utopia, relançando o envolvimento da Escola Pública local e um grupo de voluntário em torno da construção de um novo Centro Cívico. Propondo novas perspetivas, ponderamos a sua inscrição no campo da pedagogia crítica, sob a influência de Paulo Freire ou Jesús Martín Barbero, que apelou á criação de projetos de Mapeamento Educacional, deslocalizando as instituições tradicionalmente educativas para o seu exterior envolvente, assumindo o risco de criar novas possibilidades no relacionamento com comunidades urbanas.

Palavras-chave: museus, educação, democracia, participação, voluntariado.

\section{Abstract}

Through a report of the experience as a volunteer in a community project developed by Casa da Cerca, a museological institution in Almada, Portugal, we intend to bring forward a reflexion on the way it questions the action of Educational Services, helping to design new contexts and possibilities. The construction of an Intercultural Planisphere, a hand made tile mural, thought out as a public arts project, has been developed in the field of utopia, which intends to relaunch the involvement of the local public school community and a group of volunteers around the construction of a new Civic Centre. By proposing new perspectives, our aim is to consider it in the field of critical pedagogy, under the influence of Paulo Freire or Jesús Martín Barbero, who has called out for Map-Educational 
projects, bringing traditional education institutions to fields located outside themselves, assuming the risk of creating new possibilities when engaging with urban communities. Keywords: museums, education, democracy, participation, voluntary work.

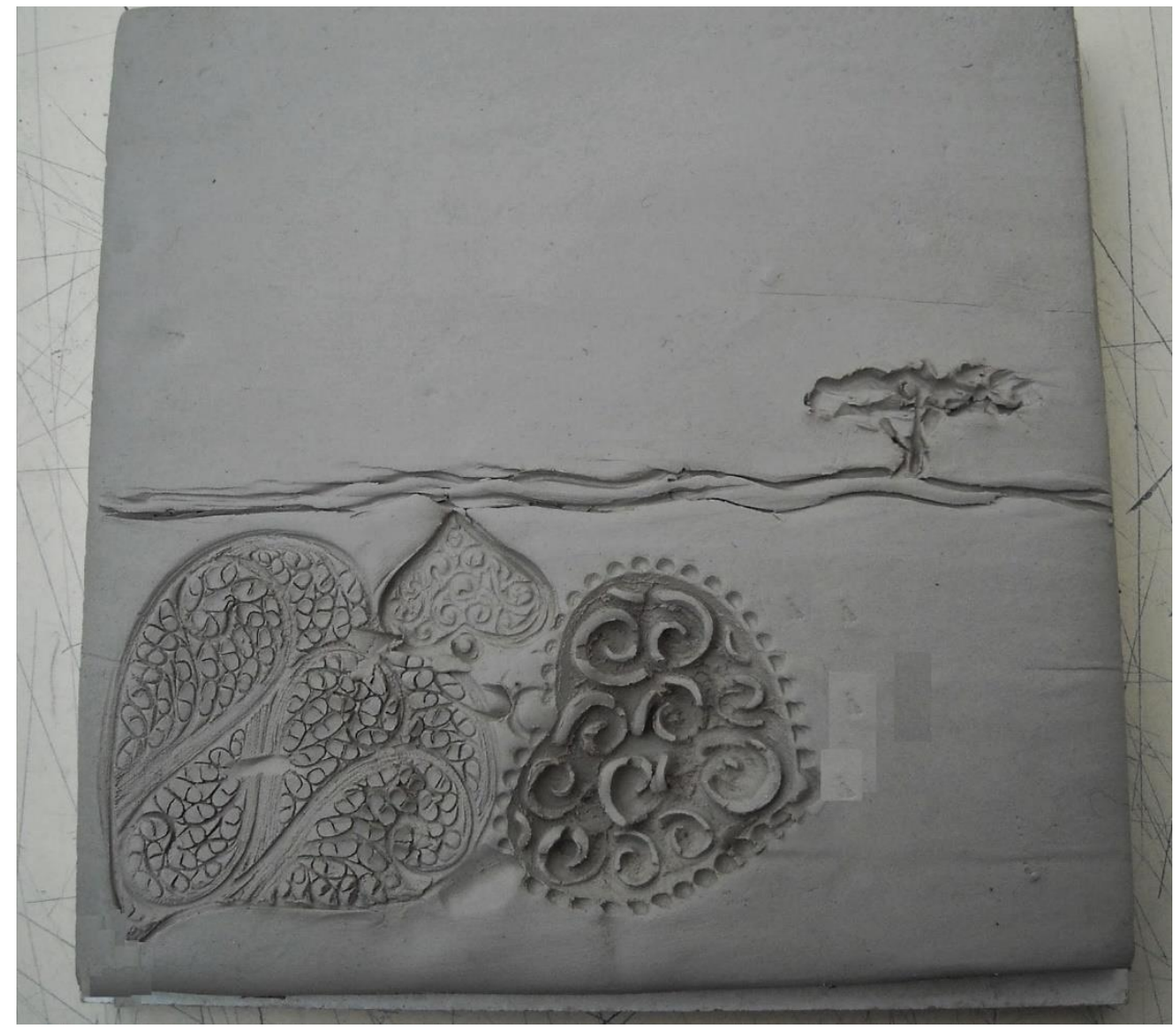

Figura.01 - Azulejo realizado numa sessão de trabalho com um dos alunos, de uma turma do $9{ }^{\circ}$ Ano.

Março 2014

Introdução.

"O Planisfério da Interculturalidade é um projeto educativo de coesão social e participação voluntária em contexto escolar, desenvolvida pela Casa da Cerca - Centro de Arte Contemporânea, nos agrupamentos do Monte de Caparica, em Almada." (Campos, 2015)

Iniciando-se em 2013, com forte envolvimento do Serviço Educativo sob a responsabilidade de Mário Sérgio Rainha Campos, o projeto que ora relatamos tornou possível a concretização de uma obra de arte pública, um grande mural de azulejos idealizado como espaço de representatividade comunitária e intervenção social no 
enquadramento da construção de um novo Centro Cívico no Monte da Caparica, distrito de Setúbal, em Portugal. Esperava-se ansiosamente pela realização de uma grande festa, na sua inauguração, depois de mais de 140 sessões que culminaram na realização de mais de 2000 azulejos, implicando a participação de todas as turmas do Parque Escolar Público da zona de implantação do projeto. Os azulejos foram realizados com a colaboração do CIEBA (Centro de Investigação e Estudos da Universidade de Belas Artes da Universidade de Lisboa) e do seu departamento de cerâmica, onde se procedeu à cozedura e vidragem de todos os elementos plásticos.

Imaginado no panorama de uma colina ventosa com vista sobre as planícies luminosas que o Tejo abre a Lisboa, cidade distante espraiada mesmo em frente, mais do que um objeto ou obra, o Projeto fundou-se em torno de uma utopia de criação de novas formas de encontro e participação, no seio de uma comunidade particularmente atingida pelas dinâmicas neoliberais de desinvestimento e alienação da Escola Pública, do Apoio Social, do Emprego. Um território urbano em contínua expansão, onde rapidamente se constatam as dificuldades inerentes ao desenraizamento e marginalidade de uma massa humana em mobilidade permanente, acompanhada de uma acelerada perda da memória e da identidade, quando os dispositivos de comunicação e mass media não são suficientes para quebrar o isolamento das pessoas ou restabelecer a experiência dos laços sociais (Barbero, 2012).

Sem o apoio de um financiamento efetivo para a força de trabalho requerida ao seu desenvolvimento, foi possível que neste projeto se encontrassem os recursos necessários no desejo partilhado por uma comunidade criativa de voluntários (estudantes, artistas plásticos, fotógrafos, viajantes, trabalhadores do concelho de Almada, profissionais de variadas áreas, professores universitários, mediadores e animadores culturais), convocados pela contagiante energia do reconhecimento da sua autonomia reflexiva, da sua capacidade de tomar decisões. Como espaço de voluntariado, o Projeto do Monumento à Multiculturalidade foi, muitas vezes, um espaço de discussão e partilha, um exercício de democraticidade, fundando-se de forma radical a procura de uma coerência política.

Mais do que partilhar ou registar o seu desenvolvimento, implantação ou concepção, que partilhei como voluntária, interessa-me refletir sobre as formas com que nesta operacionalização se joga no campo das utopias do possível, no campo de uma 
reequacionação da natureza das políticas da educação, à luz da proposta de Jacques Ranciére, que esteticiza a política e politiza a estética (Ranciére, 2009). Porque acima de tudo, me parece interessante compreender uma dimensão em que se concretizam novas possibilidades forjadas na experiência da história dos serviços educativos e das suas possibilidades de ação.

Assim, sem pretender ser exaustiva, analisarei de forma breve apenas um exemplo marcante da história e evolução das atividades em Serviços Educativos na Europa, o caso da Documenta de Kassel, focando-me principalmente nas transformações que ocorrem no campo da concepção das atividades. Esta abordagem parte da análise de duas fontes, o texto de Denise Frimer (Frimer, consultado pela última vez em fevereiro de 2012) que analisa momentos chave da evolução da educação nesta quinquenal e a sua estreita relação com a evolução dos princípios curatoriais, e também o texto de Carmen Mörsh, (Mörsh, 2009) que expõe a sua experiência como coordenadora educativa daquela quinquenal em 2009. Também encontro Nora Sternfeld (Sternfeld, 2013) que revê, de forma atualizada os princípios participatórios difundidos a partir de experiências diversas, nomeadamente as que encontra na reflexão que parte da coordenação de um Mestrado em Curadoria, Gestão e Mediação Artística na Universidade Alvaar Aalto, em Helsínquia, e a edição dos cadernos CUMMA Papers. No seu conjunto, esta análise procura explicitar um contexto que permite olhar para o projeto do Monumento da Interculturalidade no campo da mediação cultural e artística através de pedagogias participativas.

Procurarei tornar evidentes as estruturas organizacionais do projeto, bem articular ideias fundadas na relação com os participantes, ideias partilhadas no decurso das sessões de trabalho. Não tenho a ambição de fazer uma análise exaustiva da forma como se desenvolveu, mas antes procurar explicitar relações conceptuais com um campo de ação, analisado a partir das fontes já referidas.

Finalmente, procurarei encontrar-lhe o fundamento para uma recriação da ideia de educação fundada no conceito de Paulo Freire de uma educação libertária para a construção da esperança:

"Por isso é que toda a prática educativa libertadora, valorizando o exercício da vontade, da decisão, da resistência, da escolha; o papel das emoções, dos sentimentos, dos 
desejos, dos limites; a importância da consciência na história, o sentido ético da presença humana no mundo, a compreensão da história como possibilidade jamais como determinação, é substantivamente esperançosa, e por isso mesmo, provocadora da esperança." (Freire, 2000, p. 48)

Também me apoio na proposta de Jesús Martín Barbero para o desenvolvimento de Mapas-Projeto que permitam recolocar aos agentes educadores as propostas para novas formas de experienciar a territorialidade como partilha social (Barbero, 2009).

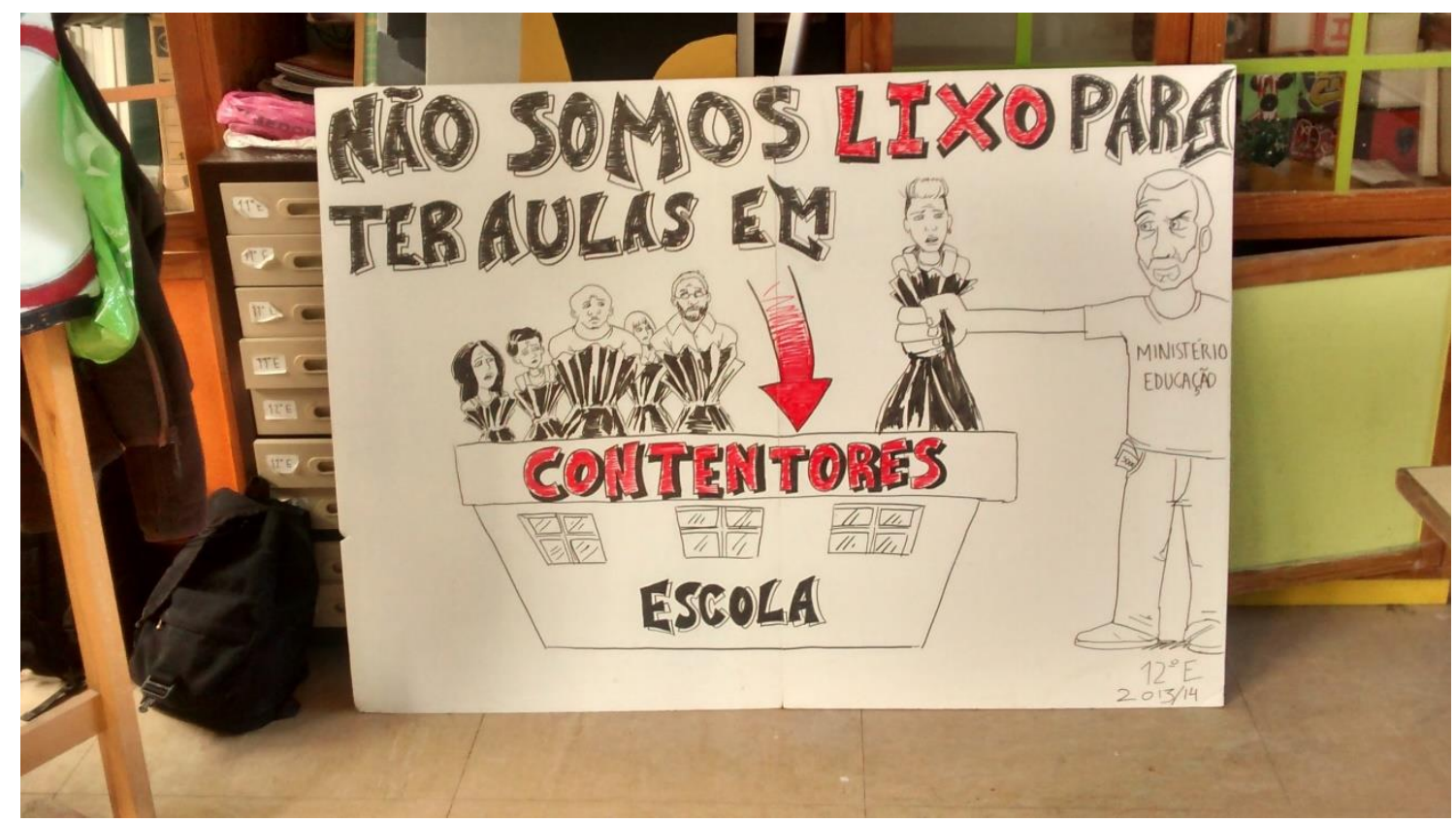

Figura.02 - Painel realizado pelos alunos da turma de uma das sessões de trabalho para uma manifestação organizada em conjunto com a Associação de Pais. Março 2014

\section{O Papel Educativo dos Museus}

Se os museus surgem no século XIX enquanto instituições de acesso público, associados ao desenvolvimento dos movimentos liberais que procuraram institui-los como espaços de afirmação da identidade cultural e ideológica dos cidadãos, estão intimamente ligados à construção da identidade cultural na Europa contemporânea, e à preservação da memória de um tempo que se desejaria abandonar: 
"Para começar com um gesto devidamente museológico, recordemos que, tal como a própria descoberta da história no seu sentido solene com Voltaire, Vico e Herder, o museu é um efeito imediato da modernização e não uma coisa situada nas suas margens ou mesmo fora delas. Não é a ideia de conservar tradições que assinala o início do museu, mas sim a de perdê-las, combinada com um desejo profundo de (re)construção." (Huyssen, 2009, p. 163).

O museu surge assim como instituição fundamentalmente educativa, um traço clássico da sua definição que inaugura aliás um vínculo primordial entre a cultura e a educação secularizado por Hannah Arendt, que colocará no centro da renovação educativa/cultural do pós-guerra, como vocação da inteligência europeia, a transmissão e o diálogo intergeracional da herança de pelo menos 25 século de história (Arendt, 1968).

A conceção e formas do desenvolvimento ou potenciação das funções educativas dos museus evoluíram ao longo do século $\mathrm{XX}$ influenciadas pela pressão que a crítica das vanguardas artísticas exerceu sobre o museu enquanto instituição e principalmente sobre a Arte enquanto veículo de transmissão de valores. As perspetivas críticas que a Filosofia e a Teoria da Arte instituíram nos anos 60 e 70 implicaram nomeadamente a instituição de um princípio participatório que implica o Museu e a própria produção artística com a acessibilidade cada vez mais alargada dos seus conteúdos às pessoas que os visitam, que além de verem ou apreciarem, são antes instados a atuarem e a participar (Frimer, consultado pela última vez em fevereiro de 2012).

Estas teorias refletem igualmente as mudanças profundas que os sistemas políticos também implicaram na concretização na Europa pós-segunda guerra mundial de novos paradigmas relacionados com o princípio democrático de participação cidadã universal bem como na defesa da Carta Internacional dos Direitos do Homem, no que é paradigmático o caso do profundo desfasamento de Portugal, onde o direito universal de voto apenas se consagra plenamente em 1974.

Interessa, no entanto, abordar a afirmação das práticas de mediação e educação cultural no âmbito dos Serviços Educativos que entram em linha de conta, a partir destas décadas, com perspetivas críticas e emancipatórias que se instauram na própria pedagogia, influenciadas nomeadamente pela edição de Pedagogia do Oprimido de Paulo 
Freire em 1968. Estas perspectivas procuram reequacionar a educação a partir da recriação da relação entre aluno e professor a partir da ideia de igualdade e liberdade.

Como exemplos, poderemos abordar o desenvolvimento extraordinário e multidisciplinar que se propõe na Documenta de Kassel em 1972, e a partir da influência do seu curador Harald Szeemann, das atividades de relação com os públicos dos museus. Este curador rompe com as convenções hierarquicamente estabelecidas entre as diferentes formas de produção artística para a criação de uma proposta inovadora. Na sua revisão das práticas curatoriais desta quinquenal de arte alemã, em 1972m está implícita também uma crítica ao formalismo e à esteticização da relação com a arte, afirmada em concordância com as práticas de vanguarda desenvolvidas pelos artistas do movimento Fluxus e as ações de ruas de Macciunas incitando à dinamização de uma relação de participação mais democrática entre públicos, artistas, curadores e educadores, apostando em estimular a imaginação das audiências em relação direta com os artistas (Frimer, consultado pela última vez em fevereiro de 2012).

Em vez de 100 dias de exposição Harald Szeemann projetou ambiciosamente 100 dias de eventos destacando-se o "Gabinete para a Democracia Direta", em 1972, de Joseph Beuys. Nesta instalação performance o próprio artista esteve presente durante todo o horário de abertura da exposição envolvendo-se em debates com os participantes sobre política, educação e ecologia, intervindo no espaço para transformar as configurações estéticas que determinavam a discussão.

Estas transformações ocorrem nos Museus e Galerias como um movimento global de enriquecimento da sua oferta cultural. Enquanto espaços de usufruição cultural, espaços de lazer, ou simplesmente de contacto com a autenticidade, os museus procuram assumir um papel crescentemente influente perante a pulverização e a crise do poder dos estados, a influência moral das religiões ou mesmo das grandes ideologias de massa, como por exemplo dos nacionalismos. Cada vez mais os museus de arte procuram destacar-se como espaços de discussão, verdadeiros fóruns públicos ou palcos onde se confrontam diferentes visões do mundo (Sternfeld, 2013). Enfim, os museus de arte assumem-se cada vez mais enquanto espaços de convivialidade, onde o encontro social se realiza de maneira eficaz emocional e culturalmente, de uma forma alternativa à cultura mais massificada, propondo novos olhares e sedimentando a construção de perspetivas críticas sobre a realidade.

Revista Digital do LAV - Santa Maria - vol. 9, n. 2, p. 167 - 180. - mai./ago. 2016 ISSN 1983 - 7348 http://dx.doi.org/10.5902/1983734821405 
A discussão sobre o valor ou a visibilidade que assumem os pontos de vista dos diferentes intervenientes é particularmente interessante, porquanto corresponde a um debate que decorre dentro desta arena que nos museus põe em confronto as diferentes áreas de saber, conhecimento e experiência dos atores envolvidos: os críticos e académicos; os museólogos e curadores; os artistas; os educadores e mediadores; as audiências dos museus; os políticos; os cidadãos ou a comunidade - que cada vez exigem mais do museu e do investimento público que ele representa; mas também as crianças, as famílias e os jovens.

Nesse sentido, revela-se também a pertinência e a importância da ação dos Serviços Educativos ao nível da programação para os públicos, cujo propósito visa, crescentemente, comunicar os conteúdos que as instituições veiculam, mas também a crítica implícita a essa instituição, patente nomeadamente nas práticas artísticas que as vanguardas estéticas, filosóficas e pedagógicas continuadamente propõem. As diferentes atividades configuram-se então como espaços de possibilidade, discussão, e aprendizagem não formal. Instaura-se uma lógica transdisciplinar, onde se desenham projetos cada vez mais virados para a inclusão social, a acessibilidade e o ativismo.

Os Serviços Educativos instauram espaços de democraticidade, chamam ao Museu novos participantes, integrados em ações que visam conferir visibilidade e representabilidade a grupos cada vez mais alargados de pessoas, numa lógica crescentemente participatória e transformista (Sternfeld,2013).

A questão mais importante é perceber de que forma esses projetos poderão ser inclusivos, no sentido em que poderão aceder à transformação das próprias condições em que a participação se concretiza. Assim, reportamo-nos ao texto de Carmen Mörsch para a edição dos cadernos sobre a educação na Documenta 12 , onde distingue quatro formas ou abordagens à educação: afirmativa; reprodutiva; desconstrutiva e transformativa (Mörsch, 2009). Segundo Mörsch as abordagens afirmativas são formas frontais de assumir e transmitir o conhecimento, enquanto as abordagens reprodutivas tendem a trabalhar com métodos assentes no diálogo e na interatividade. No entanto, em ambas as situações, os cânones institucionais permanecem inquestionados. Apenas na terceira categoria se empregam abordagens desconstrutivas. No entanto Carmen Mörsch não deixa de apontar caminhos para o futuro das metodologias educativas em 
contextos culturais, no sentido de que elas se possam tornar ou transformar em metodologias para uma nova democracia, propondo o emprego de pedagogias transformativas, as quais almejam ultrapassar o campo mais imediato da análise, mas também transformar as instituições.

Nora Sternfeld, no mesmo sentido, aponta para a necessidade de reequacionar a proposta de Jacques Ranciére, para uma compreensão mais profunda da política da estética e da educação. A autora diz-nos: "Apesar de tudo, um entendimento democrático do conceito de participação implica ser capaz de participar no processo de tomada de decisão que determina as condições dessa mesma participação, tomada de decisão e representação" (Sternfeld, 2013, p. 6).

Assim, propõe-se que os diferentes espaços de ação da educação possam ser verdadeiros reatores de uma aprendizagem para a cidadania crítica e ativa, que parece ser o passo mais certo para o desenvolvimento potencial das democracias europeias, e verificar que mais interessante do que meramente enunciar a participação dos atores sociais, se deverá encetar, em cada oportunidade, numa discussão sobre o poder de definir ou de decidir a definição.

Enfim, mais do que criar visibilidade, ou do que propor momentos de antecipação, se faz necessário questionar as regras do jogo e proporcionar momentos de encontro que sejam imprevisíveis. Propomos a entrada dos participantes do jogo educativo no terreno contencioso do que pode ou não ser discutido.

\section{O Planisfério da Interculturalidade}

Agindo fora dos muros do museu, fora das circunscrições propostas pelas suas coleções, assumindo-se como um plano de ação levado a cabo por uma instituição cultural local, de ambição nacional, para a criação de uma comunidade de participantes voluntários, e a mobilização da comunidade escolar envolvente, o Projeto para a construção do Monumento à Interculturalidade vem atuar de forma decisiva sobre a construção de realidades que transformam as próprias possibilidades de ação da Casa da Cerca.

Na sua organização o projeto contou sempre com a integração dos seus voluntários em ações debate para as quais se convocaram os participantes para uma ativa tomada de 
decisão sobre a forma, objetivos e desenvolvimento do processo. Assim, a instituição museológica, em estreita parceria com a instituição política que a tutela, no caso a Câmara Municipal de Almada, encontra espaço de intervenção na criação de tecidos ou redes de cidadãos que desejam expressar a sua voz na transformação de realidades sociais concretas. A escolha do tema, das metodologias de trabalho nas Escolas, a partilha ao final do dia, em reuniões que muitas vezes deslocam os participantes à praia (espaço fundamental da vivência daquele território) para discutir as ideias e experiências vividas, a capacidade de integrar as perspetivas críticas e de dialogar com os participantes numa construção dialética do devir, são elementos fundamentais da criação de uma coesão que estrutura a participação dos voluntários e, mais do que isso, que estrutura a criação de uma utopia de participação que fundamenta e mobiliza o próprio projeto: a recriação de fluxos e redes de convivialidade que motivem no novo Centro Cívico a reunião das pessoas para a criação cultural, para o ativismo que se vai semeando.

Esta forma de organização, baseada numa estrutura negociada com um grupo de voluntários que se autonomiza, revela-se extraordinariamente eficiente no dia-a-dia das sessões de trabalho desenvolvidas nas próprias Escolas. É principalmente esse entusiasmo que se comunica aos alunos, professores, aos assistentes operacionais que multiplicam a expressão do seu agradecimento, empaticamente ligados ao objeto que cada um é convidado a criar: um azulejo que o representará no monumento a ser construído.

Mário Sérgio, principal responsável pela dinamização e organização das ações, explica e dialoga com os participantes. Engaja-os no jogo que está para vir, entrelaçando estas duas comunidades que se encontram nas sessões de trabalho; de um lado, o grupo de voluntários que operacionalizará a criação, organização e registo de todos os azulejos, do outro, a comunidade escolar, instados a fazerem-se representar no projeto através da criação de um azulejo que se pretende que seja identitário, ou seja, que represente aquela pessoa, através da história que de si conta um objeto que previamente escolheu para o/a representar.

Eu própria trabalhei no primeiro dia de voluntariado no projeto com uma turma de Ensino de Português a Estrangeiros, num dia particularmente intenso que se prolongou desde as $8 \mathrm{~h} 30$, hora a que sempre se dava a abertura da sala de trabalho disponibilizada pela 
Escola ao elementos do Projeto, até passar das 23horas. Trabalhei com um jovem paquistanês, Tayyab Khurshid, residente em Portugal há pouco mais do que ano, que não sabia articular mais do que uma mão cheia de expressões na língua do país que agora habita. Os seus sonhos relacionam-se intimamente com a história que desenha para si, viajar até Espanha e Inglaterra, mais tarde viver no rico Irão. Lembro-me de falar sobre isso com ele, sobre o significado do objeto que escolheu para decalcar o seu azulejo: o cartão de residência em Portugal. Falamos sobre os azulejos e sobre a sua simbologia, a permanência vital da cultura islâmica em Portugal. Falamos sobre a Índia, e sobre as rivalidades nacionais, sempre com a ajuda do tradutor Google, que providencialmente eu trazia no telemóvel.

Tayyab está deslocado a 9018 km da sua terra Natal, a pequena aldeia de Mandi Bahaudin, no nordeste do país, e perguntei-me variadas vezes sobre se iria visitar o Monumento depois de inaugurado, se iria procurar o seu azulejo no Planisfério que se desenhará, se olhará para esse objeto com orgulho, se se identificará com a ideia convocada, se se sentirá mais integrado nesta comunidade que lhe é estrangeira. Tive a certeza de que a experiência foi positiva, e interessante. No dia seguinte, quando chegou à Escola depois de um dia de trabalho, Tayyab veio à sala perguntar se iríamos fazer um outro azulejo, tinha gostado da experiência, e felicitou-nos alegremente pela nossa estadia na Escola.

Os azulejos criados nas sessões de trabalho serão utilizados na composição de um Planisfério, obra colectiva, que contará ainda com a vidragem realizada nas oficinas do departamento de cerâmica da Faculdade de Belas Artes da Universidade de Lisboa. Um dos objetivos do projeto, em torno do qual se realizou uma operação de registo fotográfico e informático de todos os azulejos, é a criação de um site (para o qual ainda não há financiamento) que permita a localização de cada um dos seus elementos, a identificação, idade, turma e escola de cada um dos participantes. Poder-se-á consultar um pequeno parágrafo que explica a história, o objeto e a identidade que cada um trouxe para a realização do seu azulejo. Em cada passo da sua concretização, a forma, os objetivos e as metodologias encontram-se para uma melhor fundamentação e coerência do trabalho desenvolvido.

A história de Tayyab é talvez pouco diferente da professora alentejana que recorda as planícies de um seu outro país, com saudade. Se Tayyab está afastado inexoravelmente 
da sua terra natal por uma geografia que também tem contornos económicos, a professora aliena-se da realidade nostálgica do sentimento de pertença mediante uma distância igualmente intransponível, a do tempo. Já não sabe há quantos anos deixou o Alentejo, tem que fazer contas.

A minha impressão da semana de participação no projeto foi-se acumulando na conjugação do somatório de todas as histórias que fui ouvindo, da discussão metodológica sobre o processo com uma equipa de trabalho brilhantemente preparada no calor das discussões rigorosamente orientadas por Mário Rainha Campos, o coordenador do projeto, mas também no confronto com uma comunidade cansada da falta de condições da sua escola. A Escola Secundária do Monte da Caparica está indelevelmente marcada pela falta de condições de habitabilidade condignas, inúmeras aulas e o refeitório estão a funcionar em contentores, afetados pela falência grave do modelo de reconstrução. Ao lado de uma escola antiga e sem condições vemos o edifícioruína de uma escola nova recém construída, cujas obras foram abandonadas desde o início de 2013, quando a empresa construtora declarou falência na sequência de atrasos de pagamentos, burocracias insolúveis e problemas na gestão do projeto da Parque Escolar.

Vivia-se ali no rescaldo da manifestação que pais e alunos organizaram em novembro passado com o objetivo de chamar a atenção dos meios de comunicação para esta situação. O governo garantiu apenas medidas paliativas, as obras para a conclusão do edifício não avançariam nunca antes de setembro de 2014. Nessa mesma semana, noutras localidades do país, outros protesto ouviram-se sobre situações idênticas do norte a sul do país.

Na sala de trabalho podíamos ver o cartaz realizado pelo grupo de alunos do curso de Artes Visuais (um curso cuja oferta terminou este ano), líamos todos os dias ao entrarmos no contentor onde desenvolvíamos o projeto (um espaço frio e desagradável que os alunos habitam no seu quotidiano já há mais de 3 anos): "não somos lixo para trabalhar em contentores".

III.

Em conclusão, termino a propor que a leitura deste projeto se faça no âmbito da proposta de Paulo Freire. Analiso a possibilidade de que as sessões de trabalho com voluntários e 
comunidade escolar se possam considerar como propriamente educativas, além de artísticas, na medida em que possibilitam o desenvolvimento de uma gramática da esperança:

"Com a invenção da existência que mulheres e homens criaram com os materiais que a vida Ihes ofereceu, se Ihes tornou impossível a presença no mundo sem a referencia a um amanhã. A um amanhã ou a um futuro cuja forma de ser, porém, jamais é inexorável. Pelo contrário, problemática. Um amanhã que não está dado de antemão. Preciso de lutar para tê-lo. Mas preciso de ter dele também um desenho enquanto luto para construí-lo como o operário precisa do desenho da mesa na cabeça antes de produzi-la. Este desenho é o sonho por que luto. Uma das primordiais tarefas da pedagogia crítica radical libertadora é trabalhar a legitimidade do sonho ético-político da superação da realidade injusta. É trabalhar a genuinidade desta luta e a possibilidade de mudar. Vale dizer, é trabalhar contra a força da ideologia fatalista dominante, que estimula a imobilidade dos oprimidos e sua acomodação à realidade injusta (...)" (Freire, 2000, p. 43).

Proponho também que se considere este projeto no âmbito da proposta de Jesús Martín Barbero, para a criação de mapas-projetos que definam novos espaços de convivialidade entre as pessoas, entre as comunidades, aproveitando-se aquilo que são as ferramentas próprias das instituições tipicamente educadoras, em âmbitos novos e mais ambiciosos, que olhem para o tecido da sociedade e para o próprio território como locais de intervenção (Barbero, 2012), descentrados dos seus próprios locais, e arriscando a construção de projetos interventivos onde não se poderão controlar burocraticamente os seus participantes, pelo direito à palavra e à escuta pública dos cidadãos, pelo direito à representatividade, com a certeza de que uma sociedade plural e justa é uma sociedade de saberes compartilhados, uma cidade de hibridismos e miscigenações, é a própria ética da concepção dos projetos que se joga na discussão do alargamento e coesão das possibilidades abertas aos Serviços Educativos. 
Bibliografia

ARENDT, Hannah (1968) La crise de la cultura, Gallimard, Paris.

BARBERO, Jesús Martín Barbero (2012) "Ciudad Educativa: De una sociedade con sistema educativo a una sociedade de saberes compartidos", Educación Expandida, textos do Simpósio integrado no Festival Internacional ZEM098, Sevilla.

CAMPOS, Mário Rainha, documentação de apresentação do projeto, enviada pelo coordenador do projeto aos voluntários, vista pela última vez em www.malmada.pt/casadacerca em 12/12/2015.

FREIRE, Paulo (2000) Pedagogia da Indignação. Cartas Pedagógicas e outros escritos, ed. Ana Maria Araújo Freire, UNESP (Universidade Estadual São Paulo), São Paulo.

HUYSSEN, Andreas (2009) "Sair da Amnésia: o Museu como Meio de Comunicação de Massas", Museomania, ed. Nuno Grande, Coleção de Arte Contemporânea Público Serralves, número 12, Porto, ed. de Maio.

MÖRSCH, Carmen (2009) "At a Crossroad of Four Discourses: documenta 12 Gallery Education in between Affirmation, Reproduction, Deconstruction and Transformation", documenta 12 education II. Between Critical Practice and Visitor Services, Berlin. STERNFELD, Nora (2013) "Playing by The Rules of the Game. Participation in the postrepresentative museum", CuMMA Papers \# 1, Aalto University, Helsinqui.

\section{$\underline{\text { Netgrafia }}$}

Denise Frimer, "Pedagogical Paradigm's: Documenta's Reinvetion" / Art \& Education http://www.artandeducation.net/paper/pedagogical-paradigmsdocumenta\%E2\%80\%99s-reinvention/, consultado pela última vez em fevereiro de 2012.

Professora e mediadora cultural desde 2003, tem colaborado de forma transversal em projetos que cruzam a História da Arte Contemporânea, a programação cultural e a Educação em espaços de educação informal (Centro de Pedagogia e Animação do CCB, Museu Grão Vasco, Casa das Histórias Paula Rego) em Portugal.

Enviado em: 13 de maio de 2016.

Aprovado em: 03 de agosto de 2016.

Revista Digital do LAV - Santa Maria - vol. 9, n. 2, p. 167 - 180. - mai./ago. 2016 ISSN 1983 - 7348 http://dx.doi.org/10.5902/1983734821405 